\title{
Pharmacology and therapeutic uses of antiplatelet drugs
}

\section{E Osuch, TL Rasakanya}

Department of Pharmacology and Therapeutics, School of Medicine, Sefako Makgatho Health Science University, South Africa Corresponding author, email: elzbieta.osuch@smu.ac.za

Antiplatelet agents prevent clot formation and growth through prevention of platelet aggregation. Antiplatelet agents are essential for the prophylaxis and pharmacological management of arterial thrombosis. Appropriate use of these agents requires knowledge of their pharmacology and therapeutic uses with appropriate assessment of risks and benefits.

Keywords: antiplatelet, thromboembolism, aspirin, clopidogrel, dipyridamole, ticagrelor, abciximab

\section{Introduction}

Platelets are responsible for the initiation of haemostatic mechanisms that repair injury to the vascular endothelium. Injury to the endothelium leads to activation of platelets and pro-coagulant factors. The main physiological platelet stimuli include adenosine diphosphate (ADP), thrombin and collagen. ${ }^{1}$ Endothelial injury impairs the production of nitric oxide and prostacyclin and exposes collagen that results in platelet adherence, platelet activation, and secretion of platelet granules. Following activation, platelets undergo significant conformational changes via the GPIIb/IIla receptor on the platelet surface that make the platelets extremely adhesive and leads to binding of both von Willebrand factor (VWF) and fibrinogen. Secretion of platelet granules like ADP, serotonin, and thromboxane A2 (TXA2) stimulate and recruit additional platelets, induce vasoconstriction and have potent mitogenic effects on smooth muscle cells. ${ }^{2}$ The interactions between activated platelets and the clotting cascade, exposure of tissue factor and its interaction with factor VIla generates activated factor $\mathrm{X}$ which converts prothrombin to thrombin. Thrombin converts fibrinogen from a soluble plasma protein into an insoluble fibrin clot. ${ }^{3}$ Antiplatelet drugs are classified according to their site of action that inhibit platelet adhesion, activation, aggregation by suppressing the TXA2 pathway, ADP pathway, thrombin and phosphodiesterase (PDE). ${ }^{4}$

\section{Thromboxane A2 (TXA2) pathway inhibitors - Aspirin}

Aspirin is a non-selective, irreversible cyclooxygenase-1 (COX-1) blocker (only weakly inhibits COX-2). It acetylates a serine residue on the COX-1, inhibiting the production of prostaglandins and TXA2, a powerful platelet aggregation factor. ${ }^{5}$ The inhibiting effect lasts throughout the lifespan of the platelet (7-10 days). ${ }^{6}$ Low dose aspirin (75-100 mg orally daily) is well established for the secondary prevention of atherosclerotic cardiovascular disease (ASCVD), acute coronary syndromes, myocardial infarction, stable or unstable angina, arterial revascularisation, stroke, transient ischaemic attack, and peripheral arterial disease. ${ }^{7}$ Patients with unstable angina on aspirin treatment have a $50 \%$ risk reduction in the incidence of fatal and non-fatal myocardial infarction. ${ }^{8}$

Its use in primary prevention is still controversial and expected benefits should outweigh its potential risks. It should be avoided in patients with increased risk of bleeding including a history of gastrointestinal (Gl) bleeding or peptic ulcer disease, bleeding from other sites, age $>70$ years, thrombocytopenia, coagulopathy, chronic kidney disease, and concurrent use of nonsteroidal anti-inflammatory drugs (NSAIDs), steroids, and anticoagulants. ${ }^{9}$ The ACC/AHA 2019 guidelines on the primary prevention of cardiovascular disease recommends low-dose aspirin for adults aged between 40 to 70 years who are at higher ASCVD risk and low risk of bleeding. Low-dose aspirin should not be administered for primary prevention among adults at any age who are at increased bleeding risk and on a routine basis for primary prevention of ASCVD among adults $>70$ years. ${ }^{10}$ The United States Preventive Services Task Force (USPSTF) endorses aspirin for primary CVD prevention in adults with a 10-year risk of heart attack or stroke exceeding $10 \%$ in individuals who are not at increased risk of bleeding. ${ }^{11}$ It is also indicated in patients with increased risk factors such as diabetes mellitus, obesity, dyslipidaemia, hypertension, inactive lifestyle, smoking and family history of ASCVD. ${ }^{12}$

Aspirin use has also been shown to be effective in the prevention of colorectal cancer and colorectal adenomas. However, these potential benefits of long-term therapy must be weighed against the potential adverse effects..$^{13,14}$ Higher doses of aspirin also inhibit COX-2, which blocks prostaglandin production leading to anti-inflammatory, analgesic and antipyretic effect therefore used in the treatment of ankylosing spondylitis, fever, pain, osteoarthritis, rheumatoid arthritis, and systemic lupus erythematosus amongst others. ${ }^{15}$

Gastrointestinal tract irritation, bleeding, hypersensitivity reactions such as bronchospasm, rhinitis, urticaria, angioedema, and drug interactions are the major side-effects associated with aspirin use. Tinnitus, impaired renal function and hepatotoxicity are more likely to be experienced in higher dosages. Elderly patients are more prone to these side-effects even in lower 
dosages. It is contraindicated in patients with peptic ulceration, haemophilia, thrombocytopenia and other bleeding tendencies, including severe renal and hepatic insufficiency. Aspirin use should be avoided in children and adolescents due to the possibility of life threatening Reye's syndrome. ${ }^{4}$ It is a highly plasmaprotein bound agent, and therefore has the potential to displace other drugs (i.e. antidiabetic agents, methotrexate, warfarin) from their binding sites and thus increase the risk of toxicity. Concomitant use of other thrombolytic agents increases the risk of haemorrhage and gastrointestinal bleeding, and should generally be avoided. ${ }^{16}$

\section{ADP receptor antagonists}

ADP receptor antagonists irreversibly inhibit $A D P\left(P_{2} Y_{1}\right.$ and $P_{2} Y_{12}$ ) receptors on platelets. Antiplatelet drugs blocking $P_{2} Y_{12}$ form a cornerstone of therapy for patients at high risk of major atherosclerotic cardiovascular events, particularly those with acute coronary syndrome and those receiving percutaneous coronary intervention. ${ }^{17}$ These agents are approved for secondary prevention of events in patients with recent myocardial infarction with or without ST segment elevation myocardial infarct (STEMI), stroke and for secondary prevention of thromboembolic diseases, stroke and transient ischaemic attack, or in patients with aspirin intolerance. ${ }^{18}$ Contraindications include active bleeding, intracranial haemorrhage, and severe liver impairment. Drug interactions with aspirin, heparin, warfarin and NSAIDs increase the risk of gastrointestinal bleeding in particular. Common adverse effects include bleeding, gastrointestinal side-effects (bleeding, dyspepsia, abdominal pain and diarrhoea), and CNS effects with dizziness, paraesthesia and headache. ${ }^{19}$

\section{$\mathrm{P}_{2} \mathbf{Y}_{12}$ irreversible inhibitors - Clopidogrel, Prasugrel, Ticlopidine (not available in SA)}

Clopidogrel is activated in the liver and is six times more effective than aspirin in preventing platelet aggregation. It has superior tolerability and fewer incidences of bleeding compared to aspirin and ticlopidine. ${ }^{4}$ Due to competitive CYP2C19 inhibition by omeprazole and esomeprazole, pantoprazole should be used instead in patients requiring a proton pump inhibitor (PPI). Alternatively, another acid-lowering drug should be considered..$^{20}$ In patients who cannot use warfarin in atrial fibrillation the addition of clopidogrel to aspirin has proven beneficial. ${ }^{18}$

Prasugrel, a third generation thienopyridine, irreversibly and competitively blocks the $P_{2} Y_{12}$ receptor by forming disulphide bridges between cysteine residues, which results in a fast, powerful and sustained inhibition of platelet aggregation compared to clopidogrel. ${ }^{21}$ Prasugrel is more potent than clopidogrel in clinical settings. Prasugrel is rapidly absorbed after oral administration with $80 \%$ bioavailability. The maximum antiplatelet effect is experienced two days post initiation of therapy and platelet function is restored within two days of drug discontinuation. ${ }^{22}$ It can be co-administered with CYP3A4 inhibitors/inducers, statins and PPIs. Prasugrel is contraindicated in patients with a history of stroke or TIA and must be used with caution in patients over the age of 70 years. ${ }^{23}$
$P_{2} Y_{12}$ reversible inhibitors - Ticagrelor, Cangrelor (not available in SA)

Ticagrelor is a reversible $P_{2} Y_{12}$ receptor blocker. Unlike other theinopyridines, ticagrelor does not inhibit binding of ADP but prevents ADP-induced signalling. This enables ticagrelor to attain near maximum inhibition ( $80 \%$ ) within one-hour post administration. ${ }^{24}$ It can be used in combination with aspirin or clopidogrel to prevent thromboembolic events in patients with acute coronary syndrome. Contraindications for ticagrelor use include hypersensitivity, active bleeding, inherited bleeding disorders, intracranial haemorrhage, severe liver impairment, and the concomitant use of CYP3A4 inhibitors/inducers with a black boxed warning regarding bleeding risk with concomitant use of other antithrombotic drugs. It increases plasma levels of statins and digoxin. ${ }^{25}$ Ticagrelor is also associated with dyspnoea (14.2\%), elevated serum creatinine and elevated uric acid. ${ }^{26}$

\section{Phosphodiesterase inhibitors - Dipyridamole}

Dipyridamole blocks the platelet aggregation response by inhibiting phosphodiesterase activity, which is responsible for breaking down CAMP. In addition, the ability of platelets to reuptake adenosine is impaired, thereby resulting in increased plasma concentrations of adenosine. Dipyridamole is used in combination with other antiplatelet drugs for reducing thromboembolic complications associated with prosthetic heart valves, and is used as add-on therapy to warfarin in the secondary prevention of ischaemic stroke and TIA. ${ }^{27}$ It is ineffective when used alone.

\section{Glycoprotein IIb/IIla inhibitors - Abciximab, Epitifibatide, Tirofiban}

Glycoprotein Ilb/Illa platelet receptor antagonists block the final pathway in platelet aggregation and clot formation. These drugs are expensive and reserved for high-risk patients undergoing percutaneous coronary interventions, as an adjunct to heparin and aspirin for the prevention of ischaemic complications, short-term myocardial infarction risk reduction in patients with unstable angina, and non-STEMI not responding to conventional therapy. ${ }^{28}$ Dose reduction in renal impairment is necessary, and major side-effects include bleeding and thrombocytopenia. Although epitifibatide and tirofiban have longer half-lives than apciximab, the effects last shorter due to rapid clearance. Overdose is managed by treatment discontinuation, administering platelets and recombinant factor VIla. ${ }^{29}$

\section{Conclusion}

General practitioners have an important role to play in the prevention, treatment and risk reduction of thrombosis. In addition to pharmacological management, healthy lifestyle should always be promoted and risk factors such as smoking, obesity, familial hypercholesterolaemia, hypertension, diabetes, family history of premature ASCVD with dyslipidaemia should be assessed and treated accordingly. The decision regarding aspirin for primary prevention must involve a discussion between patients and their clinicians. 


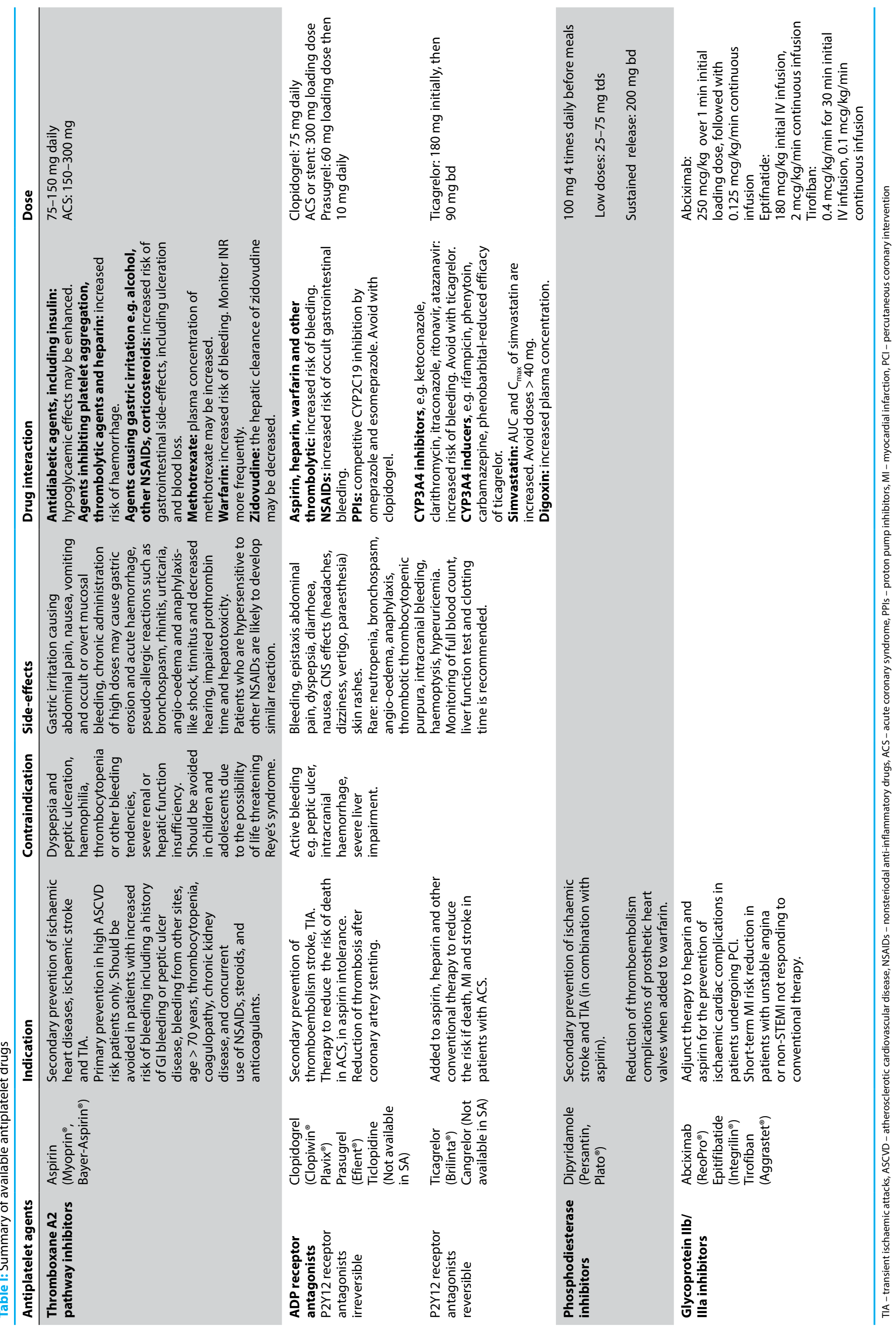




\section{References}

1. Shen J, Sampietro S, Wu J, et al. Coordination of platelet agonist signaling during the hemostatic response in vivo. Blood Adv. 2017;1(27):2767-75. PMCID: PMC5745130. https://doi.org/10.1182/bloodadvances.2017009498.

2. Pan J, Dinh TT, Rajaraman A, et al. Patterns of expression of factor VIII and von Willebrand factor by endothelial cell subsets in vivo. Blood. 2016;128(1):104-9. PMCID: PMC4937354. https://doi.org/10.1182/blood-2015-12-684688.

3. Ruggeri ZM. Platelets in atherothrombosis. Nat Med. 2002;8(11):1227-34. PMCID: 12411949. https://doi.org/10.1038/nm1102-1227.

4. Osuch E, Marais A. To clot, or not to clot - Antithrombotic therapy is the question. South African Family Practice. 2019;61(3):32-40

5. Arjun M, Deepak BL. Novel antiplatelet therapies for atherothrombotic diseases. Arterioscler Thromb Vasc Biol. 2019;39:546-57. https://doi.org/10.1161/ ATVBAHA.118.310955.

6. Clarke RJ, Mayo G, Price P, FitzGerald GA. Suppression of thromboxane A2 but not of systemic prostacyclin by controlled-release aspirin. N Engl J Med. 1991;325(16):1137-41. https://doi.org/10.1056/NEJM199110173251605.

7. Gachet C. Antiplatelet drugs: Which target for which treatment? Journal of Thrombosis and Haemostasis, 2015;13(Suppl. 1):S313-22. https://doi. org/10.1111/jth.12947.

8. Rothwell PM, Algra A, Chen Z, et al. Effects of aspirin on risk and severity of early recurrent stroke after transient ischaemic attack and ischaemic stroke: time-course analysis of randomised trials. Lancet. 2016;388(10042):365-75. PMCID: PMC5321490. https://doi.org/10.1016/S0140-6736(16)30468-8.

9. Arnett DK, Blumenthal RS, Albert MA, et al. 2019 ACC/AHA Guideline on the primary prevention of cardiovascular disease: A report of the American College of Cardiology/American Heart Association Task Force on clinical practice guidelines. Circulation. 2019;140:e596-646. https://doi.org/10.1161/ CIR.0000000000000678

10. Zheng SL, Roddick AJ. Association of aspirin use for primary prevention with cardiovascular events and bleeding events: A systematic review and meta-analysis. JAMA. 2019;321:277-87. https://doi.org/10.1001/jama.2018.20578.

11. Veronese N, Demurtas J, Thompson T, et al. Effect of low-dose aspirin on health outcomes: An umbrella review of systematic reviews and meta-analyses. Br J Clin Pharmacol. 2020;86(6):1465-75. https://doi. org/10.1111/bcp.14310.

12. Jellinger PS, Handelsman $Y$, Rosenblit PD, et al. American Association of Clinical Endocrinologists and American College of Endocrinology guidelines for management of dyslipidemia and prevention of cardiovascular disease. Endocrine Practice. 2017;23(Suppl 2):1-87. https://doi.org/10.4158/EP171764. APPGL.

13. Flossmann E, Rothwell PM; British Doctors Aspirin Trial and the UK-TIA Aspirin Trial. Effect of aspirin on long-term risk of colorectal cancer: consistent evidence from randomised and observational studies. Lancet. 2007 May 12;369(9573):1603-13. https://doi.org/10.1016/S0140-6736(07)60747-8.

14. Cole BF, Logan RF, Halabi $S$, et al. Aspirin for the chemoprevention of colorectal adenomas: meta-analysis of the randomized trials. J Natl Cancer Inst. 2009 Feb 18;101(4):256-66. https://doi.org/10.1093/jnci/djn485.

15. Arif H, Aggarwal S. Salicylic Acid (Aspirin) [Updated 2020 Apr 21]. In: StatPearls [Internet]. Treasure Island (FL): StatPearls Publishing; 2020 Jan. Available from: https://www.ncbi.nlm.nih.gov/books/NBK519032/.
16. Li L, Geraghty OC, Mehta Z, Rothwell PM; Oxford Vascular Study. Age-specific risks, severity, time course, and outcome of bleeding on long-term antiplatelet treatment after vascular events: a population-based cohort study. Lancet. 2017;390(10093):490-9. PMCID: PMC5537194. https://doi.org/10.1016/ S0140-6736(17)30770-5.

17. Mansour A, Bachelot-Loza C, Nesseler N, Gaussem P, Gouin-Thibault I. P2Y12 inhibition beyond thrombosis: effects on inflammation. International Journal of Molecular Science. 2020;21:1931. http://dx.doi.org/10.3390/ijms21041391.

18. Johnston SC, Easton JD, Farrant $M$, et al. Clopidogrel and aspirin in acute ischemic stroke and high-risk TIA. N Engl J Med. 2018;379(3):215-25. PMCID: PMC6193486. https://doi.org/10.1056/NEJMoa1800410.

19. Bellemain-Appaix A, O'Connor SA, Silvain J, et al. Association of clopidogrel pretreatment with mortality, cardiovascular events, and major bleeding among patients undergoing percutaneous coronary intervention: a systematic review and meta-analysis. JAMA. 2012;308(23):2507-16. https://doi.org/10.1001/ jama.2012.50788.

20. Wang Y, Zhao X, Lin J, et al. Association between CYP2C19 loss-of-function allele status and efficacy of clopidogrel for risk reduction among patients with minor stroke or transient ischemic attack. Jama. 2016;316(1):70-8. https://doi. org/10.1001/jama.2016.8662.

21. Motovska Z, Hlinomaz O, Miklik R, et al. Prasugrel versus Ticagrelor in patients with acute myocardial infarction treated with primary percutaneous coronary intervention: multicenter randomized PRAGUE-18 Study. Circulation. 2016;134(21):1603-12. https://doi.org/10.1161/CIRCULATIONAHA.116.024823.

22. Angiolillo DJ, Rollini F, Storey RF, et al. International expert consensus on switching platelet $\mathrm{P} 2 \mathrm{Y} 12$ receptor-inhibiting therapies. Circulation. 2017;136:1955-75. https://doi.org/10.1161/CIRCULATIONAHA.117.031164.

23. Jones R, Arps K, Davis DM, Blumenthal RS, Martin SS. Clinician guide to the ABCs of primary and secondary prevention of atherosclerotic cardiovascular disease. American Journal of Cardiology. 2018.

24. Arazi HC, Badimon JJ. Antiplatelet agents: Is twice a day a better strategy? Med Clin Arch. 2017;1(2):1-8. https://doi.org/10.15761/MCA.1000110.

25. Berwanger O, Nicolau JC, Carvalho AC, et al. Ticagrelor vs Clopidogrel after fibrinolytic therapy in patients with ST-elevation myocardial infarction: a randomized clinical trial. JAMA cardiology. 2018;3(5):391-9. PMCID: PMC5875327. https://doi.org/10.1001/jamacardio.2018.0612.

26. Koski R, Kennedy B. Comparative review of oral P2Y12 inhibitors. Pharmacy and Therapeutics. 2018;43(6):352-7.

27. Bath PM, Woodhouse LJ, Appleton JP, et al. Antiplatelet therapy with aspirin, clopidogrel, and dipyridamole versus clopidogrel alone or aspirin and dipyridamole in patients with acute cerebral ischaemia (TARDIS): a randomised, open-label, phase 3 superiority trial. Lancet. 2018;391(10123):850-9. PMCID: PMC5854459. https://doi.org/10.1016/S0140-6736(17)32849-0.

28. Boersma E, Harrington RA, Moliterno DJ, et al. Platelet glycoprotein Ilb/Illa inhibitors in acute coronary syndromes: a meta-analysis of all major randomised clinical trials. Lancet. 2002;359(9302):189-98. https://doi.org/10.1016/ S0140-6736(02)07442-1.

29. Ingerslev J, Vanek T, Culic S. Use of recombinant factor VIla for emergency reversal of anticoagulation. J Postgrad Med. 2007;53(1):17-22. PMCID: 17244965. https://doi.org/10.4103/0022-3859.30322. 